\title{
Monitoring of rice agrophiocenoses in relation to their states
}

\author{
Sergei Garkusha ${ }^{1}$, Michael Skazhennik ${ }^{1 *}$, Victor Kovalyov ${ }^{1}$, Vitaly Chizhikov ${ }^{1}$, and \\ Tatyana Pshenicina ${ }^{1}$ \\ ${ }^{1}$ Federal Scientific Rice Centre, 3 Belozerny, 350921, Krasnodar, Russia
}

\begin{abstract}
The aim of the research was to study the production process of rice agrophytocenoses and carry out their geoinformation monitoring to develop a methodology for automated mapping of their condition and forecasting yield. Small varietal differences in the productivity of photosynthesis of plants of intensive and extensive rice varieties on different backgrounds of mineral nutrition were noted. When a closed crop is formed, the nature of the distribution of assimilates over the organs of the plant and the shoot is the main physiological mechanism for the formation of different yields of the studied genotypes and their resistance to the effects of unfavorable environmental factors. With the onset of the flowering phase, the differences in the mass of panicle and stem of shoots in intensive and extensive rice genotypes are very significant. Research has been carried out to study the optical properties of cenoses of varieties and their relationship with the morphophysiological characteristics of plants and yield to monitor the state of their crops. It was shown that the value of the vegetation index (NDVI) has a positive relationship with signs of photosynthetic activity of plants and their nitrogen status. Linear regression equations have been obtained, which make it possible to assess the degree of relationship between yield and vegetation index NDVI.
\end{abstract}

\section{Introduction}

The use of remote sensing data in agriculture is mainly aimed at inventorying farmland and identifying areas of erosion, waterlogging, salinity and desertification. In recent years, research carried out in various regions of Russia, which make it possible to predict the yield of agricultural crops have gained the interest [1.2]. In rice growing in Russia, such work is practically not carried out, general approaches and methodology for assessing plant productivity based on their optical and biological properties have not been fully developed. Therefore, studies are needed to reveal the specifics of the relationship between plant productivity and remote sensing data in various soil and climatic conditions, which will improve the accuracy of the forecast.

To assess the degree of development of crops, their vegetation indices are usually used [3]. Along with the area of the assimilation surface and the chlorophyll content in plants,

\footnotetext{
*Corresponding author: sma_49@mail.ru
} 
the vegetation index is an optical and biological characteristic. In this regard, there is a need to identify the mechanisms and patterns of the relationship of these traits, which will allow obtaining more reliable information on the physiological state and production process of agricultural crops using remote sensing data [4].

The optical and biological properties of wheat plants have been investigated, which makes it possible to characterize the state of their crops [17]. UAV are also used on rice crops to determine the need for fertilizers [18]. However, the optical and biological properties of different rice genotypes have not been studied in order to predict the state of their crops. The study of these issues is important for the general physiology of plants and especially for the physiology, breeding and technology of rice cultivation.

Using high spatial resolution images obtained with the use of an unmanned aerial vehicle (UAV) to obtain spectral characteristics of vegetative plants and determine their relationships with quantitative parameters of agrocenosis in order to predict the development of the state of crops, it was found that the vegetation index (NDVI) correlated with the yield, which makes it possible to use it in mathematical models for forecasting the rice yield. Research was conducted by Teoh C.C. et al. [5, 6]. However, in these studies, in our opinion, limited data sets were used, and the developed model based on the NDVI, which was easily saturated when the leaf canopy closed, does not give sufficient forecast accuracy. Other studies have also tried to predict yield basing on plant height [7, 8, 9]. However, the relationship between height and yield usually varies with varietal characteristics. One of the important indicators of the photosynthetic activity of crops is the size of their leaf surface - the main apparatus for plants interaction with the environment. In addition, the leaf area index (LAI) is important for predicting yield. [10, 11]. Systematic analysis of the relationship between NDVI and LAI is important for yield forecasting [12]. Therefore, in this study, the vegetation index (NDVI) was determined at the critical stages of rice plant growth and then the relationship with the productivity of the agrocenosis was determined. The results obtained lay the foundation for the subsequent development of a methodology for an automated assessment of the state of rice crops and its forecast in the conditions of Russia.

Purpose of the work to study the production process of rice agrophytocenoses and carry out their geoinformation monitoring to develop a methodology for automated mapping of their condition and forecasting yield.

\section{Materials and methods}

Vegetation experiments were carried out in concrete tanks with an area of $3.6 \mathrm{~m} 2$ filled with meadow-chernozem soil taken from rice paddies at different levels of mineral nutrition according to the following scheme: 1. control (without fertilizers); 2. N12P6K6 (medium background); 3. N24P12K12 (optimal background); 4. N36P18K18 (high background) g. of active ingredient per $\mathrm{m} 2$ [13]. The studied varieties: Rapan (st), Vizit, Flagman, (intensive type), Stanichny, Sonata, Atlant (extensive type) with a seedling density of $300 \mathrm{pcs} / \mathrm{m} 2$. The experiment is two-factor: factor A - variety; B - dose of fertilizers. Phenological observations of crops and biometric analysis of plants for quantitative traits that determine grain yield were carried out according to generally accepted methods. During the growing season, the following measurements were performed using the LI-3000A device: dry and raw aboveground mass of crops, shoots and their individual organs (leaves, stem with sheaths of leaves, panicles, grain) and leaf area. The dynamics of shoot formation and the death of a part of lateral shoots were observed. Based on these measurements, the photosynthetic potential, net productivity of photosynthesis, and the rate of formation of the 
total phytomass of crops and individual shoot organs were calculated [14]. Donor-acceptor relationships were studied by the mass of the shoot and its individual organs, by the common number of spikelets and filled grains in the panicle, by the proportion (percentage) of the latter in the mass of the shoot and their relationship with the grain yield and elements of its structure. The NDVI vegetation index was determined with a GreenSeeker Handheld Crop Sensor spectrometer. Express control of the nitrogen supply of rice plants was determined with the "N-tester" device. Verification of the optical and biological properties of plants took place at the test site of "Federal Scientific Rice Centre" to optimize rice production process using a UAV with a multispectral camera.

\section{Results and Discussion}

The production process is a complex and integrated function of plants. It includes all stages of their growth and development, from seed germination to newly formed structures. The main stages of this process for cereals are seed germination and seedling formation, photosynthesis and root nutrition of plants, their growth and development, accumulation and distribution of plastic substances in plant organs and their deposition in a reserve in accordance with the genetic program of an agricultural crop. [15]. The photosynthetic activity of the crops of the studied rice cultivars on different backgrounds of mineral nutrition was judged by the leaf area index (LAI) and net productivity of photosynthesis $(\mathrm{NPPh})$.

Leaf area index (LAI) values increased with an increase in the background of mineral nutrition and reached the optimum against the background of $\mathrm{N} 24 \mathrm{P} 12 \mathrm{~K} 12$, an excess on N36P18K18; however, the net productivity of photosynthesis (NPPh) decreased.

Varietal differences in the magnitude of these traits against one nutrional background were within the experimental error. The results obtained indicate that the productivity of photosynthesis of crops at optimal and high backgrounds of NPK in intensive and extensive varieties is determined by the energy input from photosynthetic active radiation (PAR) and the availability of atmospheric $\mathrm{CO} 2$. Against the average background of fertilizers, it decreases due to the lack of leaf area of the crop, which absorbs only a part of the incoming PAR energy.

An integral indicator of the photosynthetic activity of the crops of the studied rice varieties is the value of the formation of their aboveground biomass per unit area, shown in Figure 1.

The increased intensity of its formation is observed in the phases of booting, flowering, grain formation and filling and largely depends on the background of mineral nutrition, which determines the planting density and aboveground phytomass of crops.

Against an insufficient background of mineral nutrition (N12P6K6), the aboveground mass in all varieties was significantly less than in the optimal (N24P12K12) and high (N36P18K18). Varietal differences in its value per $1 \mathrm{~m} 2$ on the same background were within the experimental error.

An important indicator of the productivity of rice varieties of different types is the number of spikelets on panicles, per unit area during the flowering phase and the proportion of their realization among caryopses during the ripening period. The total number of spikelets in panicles per $1 \mathrm{~m} 2$ in intensive varieties was significantly higher than in extensive ones. However, not all spikelets were fertile, in intensive genotypes their share was up to $89-87 \%$, and in extensive ones - 95-93\%. Determining the physiological reasons for these differences is of great interest when studying the characteristics of the production process of different types of rice varieties, which determine their different yield. These 
reasons have not yet been studied enough. However, based on the indirect data already obtained by us [16], it can be assumed that they are associated with different provision of the developing panicle structures with the initial metabolites and, with their deficiency, the number of spikelets and grains in ripening decreases, and the share of spikelets realization increases.

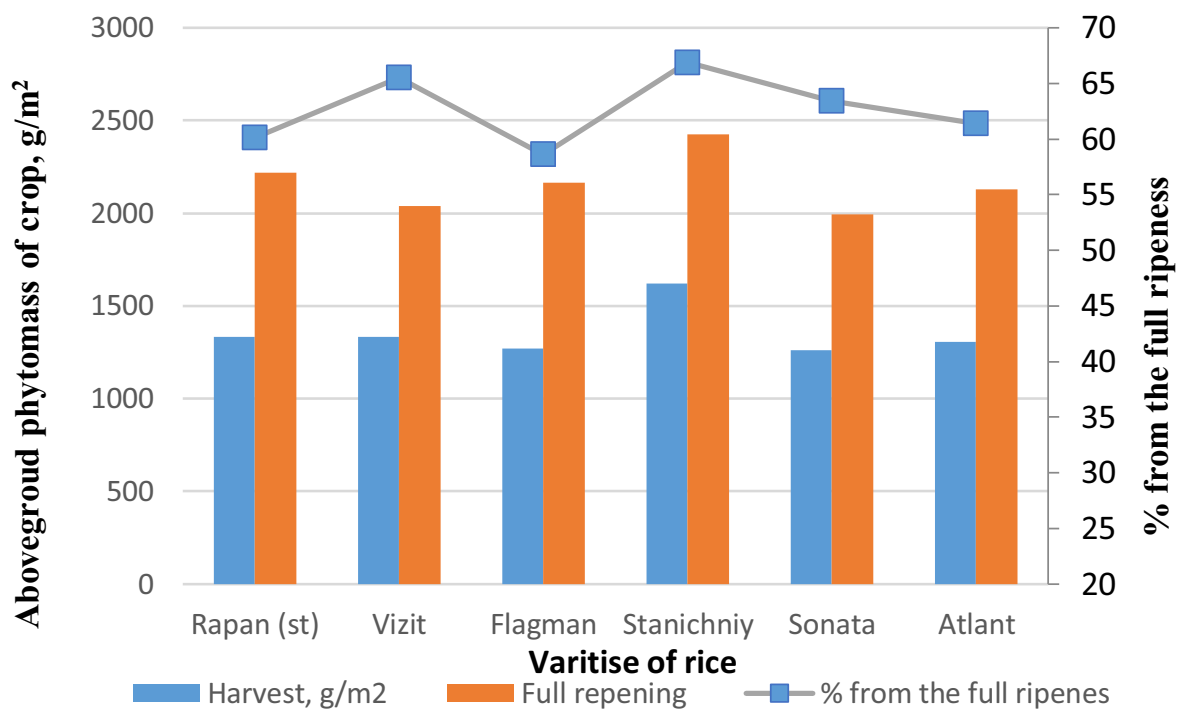

Fig.1. Aboveground mass of rice crops at the background of $\mathrm{N}_{24} \mathrm{P}_{12} \mathrm{~K}_{12}$.

The nature of the distribution of assimilates among the developing shoot organs of different types of rice varieties during the booting period has a significant effect on the unequal development of vegetative and generative organs, leading to a different proportion of stems and panicles in the total aboveground biomass of crops during the flowering period, which is the main reason for the unequal value of the coefficient of economic efficiency of photosynthesis $(\mathrm{C}, \%)$ - the proportion of grain in the total aboveground mass at full ripeness (Table 1).

Table 1. The proportion of shoot organs of rice varieties in the flowering phase and their relationship with $\mathrm{C}$, against the background of $\mathrm{N}_{24} \mathrm{P}_{12} \mathrm{~K}_{12}$.

\begin{tabular}{|c|c|c|c|c|}
\hline Variety & $\begin{array}{c}\text { Harvest } \\
\text { index C. \% }\end{array}$ & $\begin{array}{c}\text { The proportion of } \\
\text { stem in the shoot } \\
\text { mass in flowering. } \\
\text { \% }\end{array}$ & $\begin{array}{c}\text { The proportion of } \\
\text { panicle in the } \\
\text { shoot mass in } \\
\text { flowering. \% }\end{array}$ & $\begin{array}{c}\text { The proportion of } \\
\text { leaves in the shoot } \\
\text { mass in flowering. } \\
\text { \% }\end{array}$ \\
\hline & & & & \\
Rapan (st) & 48.5 & 63.7 & 16.5 & 19.8 \\
Vizit & 50.1 & 63.6 & 16.5 & 19.9 \\
Flagman & 48.1 & 61.7 & 16.0 & 21.8 \\
Stanichniy & 37.9 & 68.5 & 15.9 & 18.6 \\
Sonata & 40.9 & 66.0 & 15.1 & 19.3 \\
Atlant & 37.8 & 68.0 & 12.7 & \\
\hline \multicolumn{2}{r|}{ C correlates } & $-0.93 \pm 0.18$ & $0.68 \pm 0.18$ & $0.70 \pm 0.18$ \\
\hline
\end{tabular}


$\mathrm{C}$ value in intensive varieties Rapan, Vizit, Flagman on all three backgrounds of mineral nutrition is noticeably higher than that of extensive varieties - Stanichniy, Sonata and Atlant, which was the reason for the lower yield of the latter. At the same time, an important indicator characterizing donor-acceptor relations is $\mathrm{C}$, which has a close relationship with the yield of varieties.

Against the background of $\mathrm{N}_{24} \mathrm{P}_{12} \mathrm{~K}_{12}, \mathrm{C}$ value has a high negative correlation with the proportion of the stem in the shoot and a positive correlation with the proportion of the panicle in its total biomass during the flowering period.

Against an optimal and high background of mineral nutrition, the highest intensity of the formation of aboveground phytomass is observed in the varieties Flagman and Atlant, which differ somewhat in the LAI of crops from other varieties. This indicates that the high rates of formation of aboveground mass in these varieties are most likely associated with a more favorable arrangement of leaves in the space occupied by crop, as well as with an increased intensity of photosynthesis. A positive relationship was established between the phytomass value during the tillering period and the vegetation index $(r=0,95 \pm 0,07)$.

Rice crops respond to the application of increasing doses of fertilizers, first of all, by an increase in the leaf area caused by an increase in the size of leaves in the shoots and an increase in their number per unit area as a result of tillering of plants. The optimal level of nitrogen nutrition of plants, increasing the content of chlorophyll in leaves and the intensity of photosynthesis, simultaneously increases the optimal value of LAI. In our experiment, rice plants did not reach their optimal LAI value due to the age of the plants (6 leaves), but LAI has a close relationship with the vegetation index $r=0,90 \pm 0,09, r^{2}=0,84$ (Figure 2).

One of the important life-supporting factors of the external environment for rice varieties is the optimal provision of their crops with nitrogen during ontogenesis, which can be judged by the content of this element in the aboveground mass. Against the background of $\mathrm{N}_{24} \mathrm{P}_{12} \mathrm{~K}_{12}$, the nitrogen concentration in plants was within the optimum [16]. The data obtained are consistent with the readings of the $\mathrm{N}$-tester, which determines the intensity of leaf color during the growing season of plants, and its data are closely related to the values of LAI and phytomass.

The values of the vegetation index in the tillering phase, obtained using the GreenSeeker spectrometer, varied from 0.18 to 0.77 units depending on the background of mineral nutrition and had a positive relationship with the traits of photosynthetic activity of plants and their nitrogen status. The obtained linear regression equations make it possible to assess the degree of relationship between the yield and the vegetation index NDVI (Table 2).

Table 2. Regression equations for rice varieties.

\begin{tabular}{|l|c|c|c|c|c|}
\hline \multicolumn{1}{|c|}{ Variety } & Equation & $\begin{array}{c}\text { Coefficient 1 } \\
\text { significance } \\
\text { level }\end{array}$ & $\begin{array}{c}\text { Coefficient 2 } \\
\text { significance } \\
\text { level }\end{array}$ & $\mathbf{R}^{\mathbf{2}}$ & $\mathbf{p}^{-v a l u e}$ \\
& & & & & \\
\hline Rapan & $\mathrm{Y}=1.3536 \mathrm{X}+0.1854$ & 0.0582 & 0.4762 & 0.8870 & 0.05822 \\
\hline Vizit & $\mathrm{Y}=1.0638 \mathrm{X}+0.2750$ & 0.0646 & 0.2629 & 0.8750 & 0.06460 \\
\hline Flagman & $\mathrm{Y}=1.35389 \mathrm{X}+0.0259$ & 0.0399 & 0.9083 & 0.9217 & 0.03994 \\
\hline Stanichniy & $\mathrm{Y}=0.91099 \mathrm{X}+0.2615$ & 0.0170 & 0.0737 & 0.9663 & 0.01700 \\
\hline Sonata & $\mathrm{Y}=0.8989 \mathrm{X}+0.3087$ & 0.1190 & 0.2780 & 0.7760 & 0.11910 \\
\hline Atlant & $\mathrm{Y}=0.6861 \mathrm{X}+0.3689$ & 0.0910 & 0.1150 & 0.8263 & 0.09100 \\
\hline
\end{tabular}

$\mathrm{Y}-$ yield of rice varieties; $\mathrm{X}-$ value of vegetation index NDVI 




Fig.2. Relationship of leaf area index with NDVI in rice tillering phase.

The optimal value of the vegetation index is in the range of $0.68-0.76$ units and corresponds to the nitrogen content in the aboveground mass in the range of $3.97-4.41 \%$. [16]. These values of the vegetation index and nitrogen content should be considered optimal for the initial phase of rice tillering, when lateral productive shoots develop, and used in plant diagnostics of nitrogen nutrition of plants at the beginning of tillering.
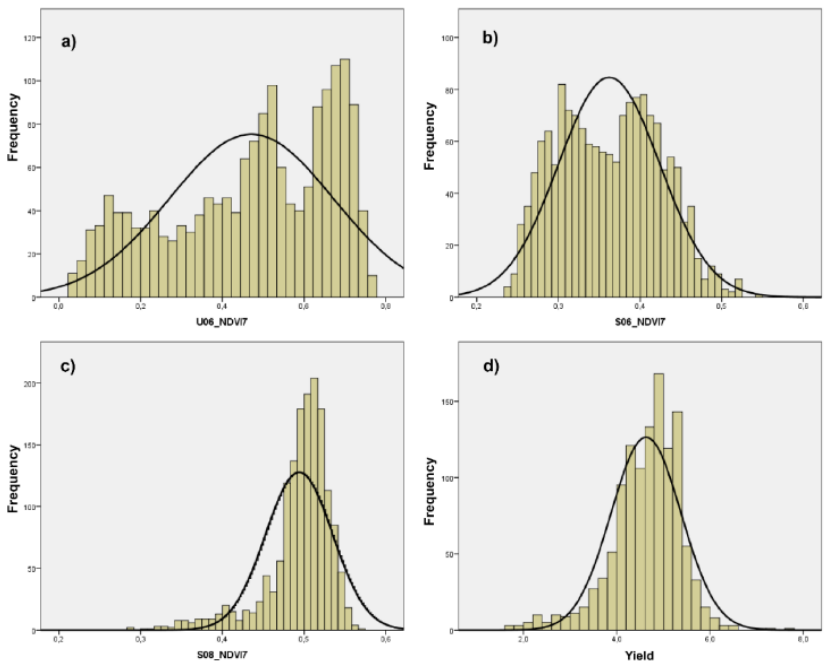

Fig.3. Histograms of the distribution of the vegetation index NDVI for plot No. 7: a) according to the UAV data (06.06.2019), b) according to the Sentinel-2A satellite data (06.05.2019), c) according to the Sentinel-2A satellite data (08.29.2019) and d) yield data (12-14.09.2019).

In addition, the verification of the optical and biological properties of plants was carried out on a test field (area 13.75 hectares) to optimize the rice production process (using a UAV with a multispectral camera and satellite data). Preliminary raster data on the vegetation 
index and yield were combined in a single table, where each row contains information on the geographic coordinates of the current pixel, NDVI values (3 terms) according to UAV, Sentinel satellite data, and yield information. Histograms reflecting the spatial distributions of the vegetation index and yield of the studied field no. 7 are shown in Figure 3.

From a brief overview of the type of frequency distribution of variables, the following preliminary conclusions can be drawn. In field 7 (variety Favorit), the histograms reflecting the distribution of the vegetation index according to the data from the UAV survey and the Sentinel-2A satellite on close dates in early June are united by their multimodality. The latter property, found on independent data, may indicate the presence of some specific micro-scale factors that determine the spatial distribution of rice crops within the field in June. At the end of August, the nature of the NDVI distribution changes, which is also confirmed by the measurement data: the histogram becomes close to unimodal, with some negative asymmetry inherent in it (the left side is elongated). Our expectations for the closeness of the shapes of the histograms reflecting the distribution of NDVI and yield were confirmed. The analysis of the correlation matrix of NDVI variables showed statistically average connection of the spatial distributions of the studied variables. The approbation of the experimental methodology for monitoring crops in 2019, based on means of remote sensing of test sites, a set of initial spatial data, means of geoinformation modeling and a statistical apparatus, should, in our opinion, be recognized as satisfactory. The results obtained make it possible to improve the method of monitoring the state of crops.

\section{Conclusions}

Thus, a feature of the production process of rice varieties of different yields is the nature of the distribution of assimilates formed in the process of photosynthesis among the plant organs, leading to a different proportion of stems and panicles in the total aboveground biomass of crops during the period of stemming, which is the reason for the unequal value of the harvesting index $(\mathrm{C})$ - the proportion of grain in the total aboveground sowing mass. $\mathrm{C}$ values of the intensive varieties Rapan, Vizit, Flagman are significantly higher than those of the extensive ones - Sonata, Atlant and Stanichniy, which led to the increased yield of the first genotypes. A more significant part of assimilates of extensive varieties was used for the formation of massive stems, which led to an increased resistance of their crops to lodging and led to a decrease in the harvesting index and yield of these genotypes. To develop a highly productive crop, it is necessary to regulate the formation of productive organs that make up the structure of the crop through a certain (optimal) nitrogen nutrition of plants. Optical-biological diagnostics, as well as morpho-biometric diagnostics in combination with chemical ones, makes it possible to answer the question of how the crop is formed depending on the level of nitrogen nutrition of plants, to establish the deficiency or excess of nitrogen at certain stages of ontogenesis, on the basis of which to develop the most rational scheme of application nitrogen fertilizers for rice. The obtained regression equations make it possible to develop a method for predicting the rice yield using the optical characteristics of rice plants.

This work was carried out with the financial support of the RFBR grant 19-416-230021.

\section{References}

1. A.Kh. Sheudzhen, T.N. Bondareva, Agrochemical service: textbook Krasnodar:

KubSA 21 (2019) 
2. V.V. Yakushev, FGBNU AFI 364 (2016)

3. V.P. Yakushev, Remote methods and means in information support of precision farming: state and prospects, Application of Land Remote Sensing Means in Agriculture: Materials of the II All-Russian Scientific Conference with International Participation. St. Petersburg. September $26-28,2018$. - SPb: FGBNU AFI $3-11$ (2018) doi: 10/25695/ agrophisica.2018.2.18484

4. B. Duan, S. Fang, R. Zhu et al., Frontiers in Plant Science 10, (2019) https://www.frontiersin.org/articles/10.3389/fpls.2019.00204/full

5. M. González-Betancourt, Z.L Mayorga-Ruíz, Colombia, DYNA 85, 47-56 (2018) https://www.researchgate.net/publication/325406776_Normalized_difference_vegetati on index for rice management in El Espinal Colombia

6. C.C. Teoh, N.M. Nadzim, M.J.M. Shahmihaizan et al., Int. J. Adv. Sci. Eng. Inf. Technol. 6 (4), 516-519 (2016)

7. J. Bendig, A. Bolten, S. Bennertz et al,. Remote Sens, 6(11), 10395-10412 (2014)

8. J. Bendig, K. Yu, H. Aasen, et al., Int. J. Appl. Earth Obs. Geoinf. 39, 79-87 (2015)

9. J. Geipel, J. Link, W. Claupein, Remote Sens. 6 (11), 10335-10355 (2014)

10. N.A. Noureldin, M.A. Aboelghar, H.S. Saudy et.al., Egypt. J. Remote Sens. Space Sci. 16, 125-131 (2013)

11. A. Verger, N. Vigneau, C. Cheron, et al. Remote Sens. Environ, 152, 654-664 (2014)

12. X. Zhou, H.B. Zheng, X.Q. Xu et al., ISPRS Journal of Photogrammetry and Remote Sensing, 130, 246-255 (2017)

13. A.Kh. Sheudzhen, T.N. Bondareva, Agrochemistry. Part 2. Technique of agrochemical research: textbook, Krasnodar: KubSAU 703 (2015)

14. M.A. Skazhennik, N.V. Vorobiev, O. A. Doseeva, Methods of physiological research in rice growing in the collection: Photosynthetic activity and production processes of phytocenoses Eagle, 109-128 (2014)

15. V.V. Kolomeychenko, Production processes in crops, Oryol, 452 (2020)

16. N.V. Vorobiev, Physiological basis for the formation of rice yield, Krasnodar Enlightenment-South 405 (2013)

17. A.F. Petrushin, E.P. Metrofanov, St. Petersburg, 81-84 (2015)

18. P.P. Aidil Rizky, M.S. Liyantono, Procedia Environmental Sciences, 24, 258-265 (2015) 